\title{
ETHICAL METHODOLOGY IN METZ'S THEORY OF UBUNTU
}

\section{Dylan B. Futter}

University of the Witwatersrand, Department of Philosophy

dylan.futter@wits.ac.za

\section{ABSTRACT}

In this article I apply Thaddeus Metz's ethical methodology to the ancient Greek ideal of $\sigma \omega \varphi \rho \circ \sigma u ́ v \eta$ in order to show that it generates a distorted account of ubuntu. If ubuntu is a virtue concept, then Metz's analytical method will not reconstruct it - because it fails to determine whether ubuntu refers to one of a plurality of fundamental virtues, the fundamental virtue, or virtue itself.

Keywords: African ethics; Ancient Greek philosophy; excellence; $\sigma \omega \varphi \rho o \sigma u ́ v \eta$ (sophrosyne); sub-Saharan morality; ubuntu; virtue

\section{1.}

In an influential article entitled "Toward an African moral theory" (Metz 2007a), Thaddeus Metz argues for a theoretical interpretation of ubuntu by application of the Rawlsian method of reflective equilibrium (Metz 2007b). ${ }^{1}$ In the scholarship emerging in response to this paper, some commentators, notably Ramose (2007: 54), have objected to Metz's reliance on a "strictly analytic methodology" (Metz 2007c: 376) in the formulation of an African moral theory. In this paper I shall attempt to support this line of objection by showing that Metz's methodology does not properly delineate the conceptual role of ubuntu in African moral language.

1 Although Metz has developed his view extensively in further writings, the core of his account appears to remain much the same as that given in (2007a).

\section{UNISA}


2.

Metz's method is to begin by identifying a set of core ethical intuitions or judgments that "most friends of ubuntu firmly hold" (Metz 2007a: 323). ${ }^{2}$ He then divides this set of ethical intuitions into two groups. The first group consists of global ethical judgements widely shared by Western people and "adherents of ubuntu" (324), having to do with prohibitions on theft, murder, rape, and so on (321). The second group consists of local intuitions said to be characteristic of the "largely black and Bantu-speaking" people of sub-Saharan Africa, ${ }^{3}$ and includes the wrongness of making policy decisions "in the face of dissent" (324), not upholding traditions and rituals, and failing to marry and have children. ${ }^{4}$

Given this presentation of the data, Metz "seek[s] a theory inspired by ubuntu that best accounts for both of [the] two groups" of moral judgments (323). This is to say, more precisely, that he searches for a principle that "entails and well explains" the intuitions to which the "friends of ubuntu" are committed (323-324). The principle sought is therefore supposed to give a rational reconstruction of $u b u n t u$ rather than some other evaluative concept or perspective. Metz makes this explicit by referring to an account of the ethical data as, inter alia, a "theoretical interpretation of ubuntu" (328), a "principled rendition of ubuntu" (329), a "construal of ubuntu" (330), and an "understanding of ubuntu" (330).

My approach in supporting the claim that Metz's methodology fails to give a satisfactory account of ubuntu will be to dramatise inferences parallel to what appear to be Metz's inferences in his attempt to rationally reconstruct (322) talk of

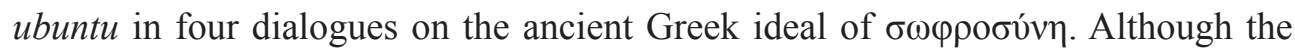
virtue of $\sigma \omega \varphi \rho \sigma^{\prime} v \eta$ is alien to contemporary Western people (Hamilton and Cairns 1961: 99), ${ }^{5}$ the strangeness of $\sigma \omega \varphi \rho о \sigma o ́ v \eta$ is presently an advantage, since it directs attention to the logical relationships that obtain between $\sigma \omega \varphi \rho \circ \sigma v i v \eta$ and other

2 References to Metz (2007a) will hereafter be indicated in the text by page numbers within round brackets.

3 Metz explains that he is referring to "tendencies, not essences" (2007: 324) [emphasis added].

4 For further details, see Metz (2007a: $324 \mathrm{ff})$.

5 It is generally agreed that "there is no adequate translation [of $\left.\sigma \omega \varphi \rho \sigma^{\prime} v \eta\right]$ in modern European languages" (Cooper 1997: 639). Standard English translations such as sound-mindedness, temperance or moderation are in various ways unsatisfactory, as a cursory reading of Plato's Charmides makes clear. 
virtue concepts. ${ }^{6}$ For this reason, I shall not attempt to clarify the notion beyond the following sketch, which will serve to orient the reader:

Arrogance, insolent self-assertion, was the quality most detested by the Greeks. [ $\Sigma \omega \varphi \rho \circ \sigma u ́ v \eta]$ was the exact opposite. It meant accepting the bounds which excellence lays down for human nature, restraining impulses to unrestricted freedom, to all excess, obeying the inner laws of harmony and proportion. (Hamilton and Cairns 1961: 99)

It is important to notice that although the account I give of the logical behaviour of

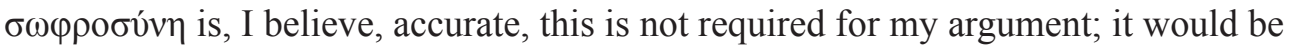

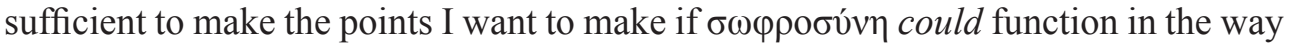
I shall suggest, and of this there is no doubt.

\section{3.}

The first dialogue below formally dramatises an inference parallel to what appears to be Metz's inference from the conjunction of global and African intuitions to the concept of $u b u n t u$. But in this case the inference is from global and Spartan intuitions to the concept of $\sigma \omega \varphi \rho \sigma^{\circ} v$ m.

\section{DIALOGUE I}

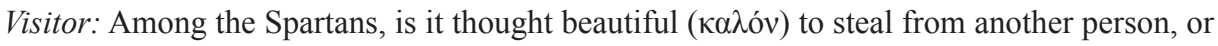
to betray one's friends?

Spartan: Certainly not.

Visitor: Do you say that that it is beautiful for a young man to honour his mother and father? Spartan: Very much so.

Visitor: So, then, do you say that it is $\sigma \omega ́ \varphi \rho o v \alpha$ for the young to honour their parents, and not $\sigma \omega ́ \varphi \rho o v \alpha$ for a man to steal from another, or to betray his friends?

Spartan: I do not.

6 This would not be possible, or possible to the same extent, if I had selected justice or courage, concepts that are shared by Ancient Greek and contemporary Western ethical traditions. The account of $\sigma \omega \varphi \rho о \sigma u ́ v \eta$ assumed in this paper is largely drawn from Plato's Charmides. This is perfectly compatible with a Spartan emphasis since the dialogue's primary interlocutors, Charmides and Critias, are associated with the pro-Spartan oligarchy of 404BC installed after the Peloponnesian War; the entire dialogue is, as Schmid (1981: 145) observes, steeped in the "honour

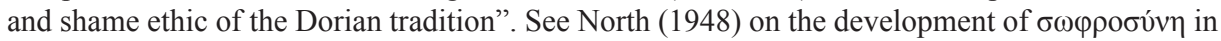
Greek literature. 
For the friends of $\sigma \omega \varphi \rho о \sigma u ́ v \eta$, respect for elders is $\sigma \omega \varphi \rho \omega v .^{7}$ However, theft and murder do not naturally fall under the concept of $\sigma \omega \varphi \rho \circ \sigma u ́ v \eta$, but under the concept of justice. ${ }^{8}$ Therefore, the Spartan interlocutor does not accept the inference from the global and Spartan intuitions to the concept of $\sigma \omega \varphi \rho о \sigma u ́ v \eta$. Therefore, any further inference from the global and Spartan intuitions to a "principled rendition" (329) of $\sigma \omega \varphi \rho \sigma^{\prime} \eta \eta$ would be misguided.

As noted above, Metz's goal in his article is to rationally reconstruct values "associated with talk of "ubuntu" (322); he claims to be seeking "a theory inspired by ubuntu that best accounts for both [global and local African] intuitions" (323). However, if ubuntu is like $\sigma \omega \varphi \rho o \sigma v ́ v \eta$ in being one particular virtue, and if the intuitions expressing global and distinctively African moral judgments do not fall under the same virtue concept, then Metz's inference from the global and local intuitions to ubuntu will be invalid. The objection is not that the inference is invalid because it is an inference to the best explanation, but rather that the conceptually necessary conditions required for an abduction that generates an account of ubuntu (rather than some other concept) are not fulfilled because there are (ex hypothesi) ethical intuitions included in the data set that do not fall under the concept of $u b u n t u$.

Some of Metz's formulations suggest that he thinks of $u b u n t u$ as a term referring to a cluster of values rather than a single virtue. ${ }^{9}$ If this is so, then he might avoid the invalid inference, but only at the cost of distorting the logical character of the ubuntu concept. For the scholarly literature on African ethics provides compelling evidence for taking $u b u n t u$ to refer primarily to an attribute of character or of soul. ${ }^{10}$

\section{4.}

The next dialogue permits the inference from distinctively Spartan intuitions to the concept of $\sigma \omega \varphi \rho о \sigma v ́ v \eta$. What is in question is the relationship between $\sigma \omega \varphi \rho \sigma^{\prime} v \mathfrak{v}$ and the other virtues.

7 See Xenophon, Memorabilia 3.5.15, where Pericles asks: "When will the Athenians respect their elders in the same way that the Spartans respect theirs, instead of despising everyone older than themselves, beginning with their own fathers?" (Garland trans.; qtd. in [2008: 66]) See also Herodotus 2.80 and Plutarch, Life of Lycurgus, 15.2 and 21.4. Cf. North's reference to Telemachus's modesty in dealing with his Spartan host, Menelaus (North 1948: 5).

8 See Plato, Charmides; cf. Rep. 443a. If this is not accepted, the point can be made conclusively in terms of $\dot{\alpha} v \delta \rho \varepsilon i ́ \alpha$.

9 See e.g. Metz's reference to "values associated with the largely black and Bantu-speaking peoples" (2007a: 321) and "values associated with the term "ubuntu"” (ibid. 323).

10 See e.g. Gade (2012) and Van Niekerk (2013: 86-89). Van Niekerk quotes Semantimba Barlow as claiming that "ubuntu is ascribed to a person in whom virtue conglomerates" (qtd. on 87). Cf. also Gyekye (2011). The sense of ubuntu as a philosophy outlined by Gade is plainly a derived and secondary use of the term. 


\section{DIALOGUE II}

Visitor: Do you say that that it is beautiful for young people to honour their mothers and fathers?

Spartan: Very much so.

Visitor: And is it not the case that, for the Spartans, a man who does not marry does not act beautifully?

Spartan: That is true.

Visitor: And do you then say that the things mentioned are $\sigma \omega ́ \varphi \rho о v \alpha ?$

Spartan: I do.

Visitor: And if something is $\sigma \omega ́ \varphi \rho o v \alpha$, then this is on account of $\sigma \omega \varphi \rho \circ \sigma u ́ v \eta ?$

Spartan: Yes.

Visitor: So, then, do you say that $\sigma \omega \varphi \rho \circ \sigma u ́ v \eta$ is the most beautiful of the things pertaining to

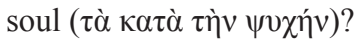

Spartan: No, I do not.

Although $\sigma \omega \varphi \rho \circ \sigma u ́ v \eta$ was "to the Greeks...an ideal second to none in its importance," being "the spirit behind the two great Delphic sayings, 'know thyself' and 'nothing in excess" (Hamilton and Cairns 1961: 99), it is one of a plurality of fundamental ideals. Thus, it does not follow from the fact that certain characteristically Spartan intuitions fall under the concept of $\sigma \omega \varphi \rho \circ \sigma v ́ v \eta$ that $\sigma \omega \varphi \rho \sigma^{\prime} v \dot{v} \eta$ is the most important virtue. With application to Metz's argument, the point is that even if the African intuitions enumerated were to fall under the same particular virtue concept, it would not follow that ubuntu is the fundamental ethical ideal. ${ }^{11}$ Hence the inference from ubuntu to more general claims about African ethics is problematic.

The specific point underlying the Spartan interlocutor's rejection of the inference from $\sigma \omega \varphi \rho \circ \sigma 0 ́ v \eta$ to "the most beautiful of the things pertaining to soul" is the omission of $\alpha v \delta \rho \varepsilon i ́ \alpha$ - literally manliness, but normally translated as courage (cf. Plato, Laws, 628c ff.). This concern carries over to the discussion of ubuntu in an interesting way. The scholarly literature on African ethics is - as far as I can tell - striking in its exclusion of the values associated with courage. ${ }^{12}$ This is surprising, not only because the need for courage seems to arise from fundamental features of

11 This point would apply even if it so happened that all global and local African intuitions outlined by Metz could be subsumed under the ubuntu concept.

12 I have not found courage discussed in any of the sources cited in this paper. 
the human condition, but because some Bantu peoples, such as the amaZulu, seem to have been Spartan-like in their valorisation of war. ${ }^{13}$ Therefore, inasmuch as courage is paradigmatically the virtue of the warrior, ${ }^{14}$ it seems likely that it would have occupied an important place in their ethical vocabulary. ${ }^{15}$

Metz needs to clarify the relationship between ubuntu and other virtues in African ethical thought. Formulated as questions: what is the place of manly courage, or wisdom, or justice, in the African traditions? Are ubuntu and courage both fundamental ideals, with neither one taking priority over the other? And if so,

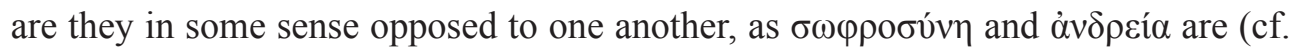
Plato, Statesman, 306b-307b)?

\section{4.}

The third dialogue again permits the inference from the distinctively Spartan intuitions to the concept of $\sigma \omega \varphi \rho о \sigma v ́ v \eta$. The question this time is the relationship between $\sigma \omega \varphi \rho \circ \sigma v ́ v \eta$ and virtue ( $\dot{\alpha} \rho \varepsilon \tau \eta ́)$.

\section{DIALOGUE III}

Visitor: Do you say that it is beautiful for a young person to honour his mother and father?

Spartan: Very much so.

Visitor: And is it not the case that, for the Spartans, a man who does not marry does not act beautifully?

Spartan: That is true.

Visitor: And do you say that the things said ( $\tau \grave{\alpha} \lambda \dot{\varepsilon} \chi \theta \mathrm{e} v \tau \alpha)$ are $\sigma \omega ́ \varphi \rho o v \alpha ?$

Spartan: I do.

13 See e.g. Laband (1995).

14 See Aristotle, EN 1115b12-13. The Athenian stranger in Plato's Laws attributes the following to the Spartan poet Tyrtaeus: "I'd not mention a man, I'd take no account of him, no matter...if he were the richest of men, no matter if he had a huge number of good things...unless his prowess in war were beyond compare" (629a-b; Saunders trans.).

15 I am grateful to an anonymous referee for Phronimon for pointing me to T. Waetjen's discussion of the "martial reputation of Zulu manhood" (2004: 2) that "developed in the wake of King Shaka kaSenzangakhona's exploits". The same referee adds: "Recall that during the Frontier Wars, even the enemy considered the Xhosa 'real men' because they fought bravely... [As] one nineteenthcentury colonial Captain stated, if trapped a Xhosa warrior would 'stand up like a man and throw his last assegai' (J. Alexander [1837] 1: 338, cited in Jeffrey B. Peires, The house of Phalo: A history of the Xhosa people in the days of their independence (Berkeley: University of California Press, 1982), 139)". 
Visitor: And if something is $\sigma \omega ́ \varphi \rho o v \alpha$, then this is on account of $\sigma \omega \varphi \rho o \sigma v ́ v \eta ?$

Spartan: Yes.

Visitor: So do you say that $\sigma \omega \varphi \rho o \sigma v ́ v \eta$ is $\dot{\alpha} \rho \varepsilon \tau \eta ? ?$

Spartan: No, I do not.

Although $\sigma \omega \varphi \rho о \sigma u ́ v \eta$ was to the Spartans a very fundamental ideal, it does not

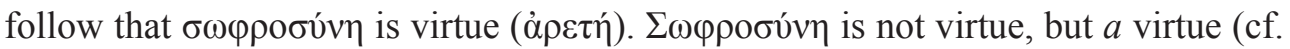
Plato, Meno, $73 \mathrm{~d}$ f.). If, therefore, $u$ buntu were a particular virtue, the inference from ubuntu to virtue itself would fail, even if the global and local intuitions enumerated by Metz could all be subsumed under the concept. On the other hand, if ubuntu is like $\alpha \rho \varepsilon \tau \eta ́$ in referring to the genus of which (e.g.) wisdom, justice, courage and

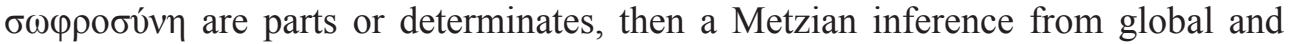
local ethical intuitions to ubuntu will go through. But the formal validity of the inference will incur certain costs, in particular, those of conceptual imprecision and loss of ethical structure. A parallel inference from the act-types representative of global and local Spartan intuitions directly to the concept of $\alpha \rho \varepsilon \tau \eta$ flattens out the conceptual landscape. The specific domains of excellence which make up virtue as a whole are elided.

Is ubuntu one virtue among many or virtue itself? Some of the literature on African ethics seems to support the idea that $u b u n t u$ is equivalent to virtue itself. ${ }^{16}$ One line of argument in support of this claim discernible in the scholarship is an appeal to etymology. ${ }^{17}$ The word ubuntu is the abstractive form of -ntu, which is the root of the Nguni word for "man" or "human being". ${ }^{18}$ Since the reference is to the human being as a whole, the inference is made that ubuntu corresponds to the concept of human virtue or excellence. Or, at any rate, this implication seems to have been embraced by those who have given perfectionist interpretations of the concept. $^{19}$

In response to this line of reasoning, two tentative remarks: first, in the interviews conducted by Christian Gade (2012), ubuntu is explicated in terms of what seems to be a very specific set of virtues having to do with kindness, forgiveness, empathy

16 Of those writers cited by Metz, see e.g. Tutu (2000: 31), Ramose (1999: 52) and Shutte (2001: 30).

17 Cf. Mangosuthu Buthelezi's remark that "'humanism' is the nearest translation of what ubuntu is", reported in Gade (2012: 492). See also Metz (2007a: 323) and Eze (2010: 160-61).

18 The root is taken to originate in a proper name; for Ntu is thought to be the forefather of the Bantu peoples. "According to oral historian Senzo "'Maswidi"” Mkhanyiseni Mbatha as far as he knows the first black person that we hear of is 'Ntu', the ancestor of all African people. The plural noun 'abantu' is a result of Ntu's name being used in plural form to categorise his descendants" (Hlatshwayo 2010).

19 See e.g. Ramose (1999) and the other authors cited by Metz on p.331. Cf. also Van Niekerk (2013: 98-100). 
and compassion. ${ }^{20}$ It is difficult to believe that this emphasis, even if referring to the fundamental human ideal, is compatible with an analysis of ubuntu as the generic term under which other virtue concepts are ordered. Secondly, it is worth noticing that the move from human being or man - the ambiguity is crucial - to virtue itself would be misleading in the Greek case, since the word $\alpha v \delta \rho \varepsilon i \alpha$ is linguistically an abstractive substantive derived from "man" ( $\dot{\alpha} v \eta \dot{\rho} \rho$; from PIE *ner). ${ }^{21}$ Hence the nature of the human being is here interpreted in terms of man, a masculine human ideal. ${ }^{22}$ The absence of courage from the topography of African ethics seems to correspond, in a curious way, with a Christian and Kantian articulation of humanity.

\section{5.}

Given uncertainty about the conceptual role of $u b u n t u$, it might seem better for Metz to build up his account from the two groups of African ethical intuitions directly to the concept of rightness, bypassing the notion of ubuntu altogether and talking more generally in terms of an African ethical theory. ${ }^{23}$ However, this manoeuvre will both leave him vulnerable to the objection that the selected act-intuitions give a lopsided ubuntu-heavy picture of the African ethical worldview, and would invite some additional questions about the envisioned transformation of a virtue concept into the language of right action.

\section{DIALOGUE IV}

Visitor: Among the Spartans, is it thought beautiful to steal from another person, or to betray one's friends?

Spartan: Certainly not.

20 This is also the sense that one gets from the explanation of ubuntu given by President Nelson Mandela (2006).

21 Cf. also the fact that "virtue" derives from the Latin virtus: “ "...manliness; valour, bravery, courage (in war); excellence, worth, from vir "man"..." See Harper (2007).

22 The word $\alpha v \theta \rho \omega \pi \mathrm{s}$, a word for both a man and for the human being, is often analysed as combination of $\alpha v \eta \dot{\rho} \rho$ and $̋ \psi$, that is, "man-faced". See Harper (2007).

23 It should be noted that Metz's account is developed in dialogue with several African philosophers, some of whom seem to have attempted a similar conversion of African ethical concepts into the rightness vocabulary of contemporary normative ethics (Metz 2007a: $329 \mathrm{ff}$.). The concerns expressed below will apply a fortiori to these endeavours. I will not argue that this type of project is always illegitimate, although I do believe it is always problematic. The root of my concern can be expressed by saying that conceptual conversion in the absence of a clear delineation of the contours of the source ethical language is bound to involve distortion. See also the discussion in $\S 6$. 
Visitor: Do you say that it is beautiful for a young man to marry and beget children?

Spartan: Very much so.

Visitor: Well, then, do you say that it is right for a young man to marry and beget children, and wrong for one to steal from another person, and to betray his friends?

Spartan: No, I do not.

Visitor: So do you say that is wrong for a young man not to marry and have children, and right for one to steal from another person, and to betray his friends?

Spartan: I least of all.

The Spartan interlocutor will not accept the move to rightness; he does not have the concept. ${ }^{24}$ The closest concepts to rightness in the Greek tradition are $\tau$ ò $\pi \rho \varepsilon ́ \pi$ ov and

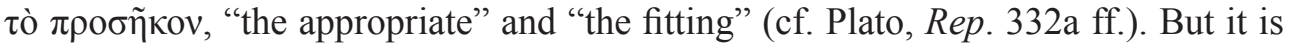
revealing that neither Plato nor Aristotle devotes any attention to these notions in their ethical writings. At the very least, therefore, it cannot be doubted that the virtues such as wisdom, justice, courage ( $\alpha \nu \delta \rho \varepsilon i ́ \alpha)$ and $\sigma \omega \varphi \rho \sigma^{\prime} v \eta_{\eta}$ are, for the Hellene, immeasurably more important than rightness and fittingness. Thus the inference to rightness would not strike the Spartan interlocutor as correct, or obviously correct, as it would strike us, and this reveals much about the structure of his ethical language. ${ }^{25}$

A basic question for Metz is thus the place of the concept of rightness in the original ethical vocabulary of the Bantu-speaking people. ${ }^{26}$ If the concept of rightness is not part of the original conceptual vocabulary, then the attempt to transpose the ethical intuitions of African people into the language of right will involve a fundamental deviation from the way that they think of themselves. To be sure, it is obvious that the notion of right action has a long history in Africa, in part because of the influence of Christianity and Islam. But it is not clear that this will help Metz's cause; for he appears to be attempting a reconstruction of indigenous African ethical ideals.

24 Although the concept of justice covers the first two intuitions (theft and betrayal), the value of marriage and bearing children is not fundamentally a matter of justice.

25 It seems to me that if rightness were understood as a general term of approbation, then the Spartan would accept the inference to rightness, although it would strike him as strange and distorting, perhaps in a way that is akin to the strangeness of describing torture and rape as "impolite". On the other hand, if rightness were understood more strongly as indicating an obligation, then the Spartan would not accept the inference. For this, he would use the term justice.

26 See Gyekye (2011: section 2) for discussion of the way that various African languages express judgments of right and wrong in terms of judgments of character. Notably, Gkekye claims that the Bantu language of Southern Sotho has "no words that are the direct equivalents of 'ethics' or "morality"' (ibid.). 
6.

As I understand him, Metz's goal in the paper is to transform the fundamental ethical opinions of Bantu-speaking sub-Saharan African people into the language of English and of right action (322). If the term "translation" is restricted to natural language and (artificially) set aside, and "transposition" is used for the conceptual conversion of virtue concepts into the language of right action, then this project can be said to be a matter of systematic ethical transposition. As he writes:

I go beyond moral anthropology in that I seek to unify variegated commonsensical beliefs and to argue that one such unification (which may not be widely held) is better than others. [322; emphasis added]

Metz's method of systematisation, apparently modelled on Rawls's reflective equilibrium (cf. Metz 2007c: 233), is roughly as follows:

1. Begin with two groups of "ubuntu" intuitions transposed into the language of right action: group 1 (= global); group 2 (= local).

2. Now consider principles $\mathrm{P}(1)-\mathrm{P}(\mathrm{n})$ as candidates for unifying these intuitions.

3. $P(x)$ is preferable to $P(y)$, if (a) $P(x)$ explains group 1 and group 2 intuitions whereas $\mathrm{P}(\mathrm{y})$ does not, or (b) P (x) explains them better than $\mathrm{P}(\mathrm{y})$.

By application of this method, Metz argues that "the most justified normative theory of right action that has an African pedigree is the requirement to produce harmony and to reduce discord, where harmony is a matter of identity and solidarity" (340).

Questions can be raised about both the "transposition" and the "systematic" components of the project. To begin with transposition, if ubuntu is, as seems to be the case, a virtue term, ${ }^{27}$ then Metz aims to convert thick moral concepts into thin moral concepts. ${ }^{28}$ This is a very difficult enterprise and risks losing much of the conceptual structure of the source vocabulary. In addition, if ubuntu is, as appears to be the case, a particular virtue that is not transparently related to justice, then things are even worse. The transposition of certain kinds of virtue concepts into the language of right is a hopeless enterprise. For example, one can display $\sigma \omega \varphi \rho о \sigma u ́ v \eta$ by respecting one's elders, doing things in a quiet and orderly manner, by blushing, and feeling shame (cf. Plato, Charmides 158c). But it is obviously impossible to express these actions and qualities in the language of right, which is, as its etymology indicates, fundamentally the vocabulary of law. ${ }^{29}$ And something similar would be the case if ubuntu were at all akin to the virtue of $\sigma \omega \varphi \rho \rho \sigma o ́ v \eta$, which has an adverbial force,

27 See note 10 above. I am here setting aside the question of whether ubuntu is a virtue, the fundamental virtue, or equivalent to virtue itself.

28 For this distinction, see Williams (1985: 130, 141-142).

29 As an adjective, "right" can be derived from the "Proto-Germanic *rekhtaz"; it is cognate with the German word recht. See Harper (2007). 
applying to the manner in which an action is done, rather than, predominantly, a determinate array of act-types.

Moving on to the systematisation component, the following points apply. First, the question of what unifies the global and local ethical intuitions makes sense on the assumption that what unifies the moral act-types is not already known. But here it is important to notice, in regard to the Spartan dialogues, that the different intuitions about ethical action are already unified by different virtue concepts. The appearance of disunity is manufactured by abstracting the acts from the virtues and transposing them into the language of rightness. If there is a question of unity here, as of course there is, it will arise at the level of the virtues themselves.

Secondly, two senses of better unification are discernible in Metz's method of systematisation. The first has to do with faithfulness to the original ethical vocabulary; the second has to do with the goal of devising a plausible normative theory. ${ }^{30}$ But these two senses of unification can come apart, as is indicated by his handling of "the dominant [perfectionist] interpretation of African ethics" (331). ${ }^{31}$

Although Metz has some reservations about the unifying power of the perfectionist account, he allows that the enumerated local and global intuitions can be unified by a duty to "maximise self-realisation" of one's communal nature (332). But he argues that the self-regarding orientation of the explanation is unsatisfying:

If I ask why I should help others, for example, this theory says that the basic justificatory reason to do so (though not my proper motive for doing so) is that it will help me by making me more of a mensch or a better person. However, a better fundamental explanation of why I ought to help others appeals not to the fact that it would be good for me...but to the fact that it would (likely) be good for them... (332)

Crucially, this objection enables him to move away from a perfectionist account of ubuntu in the direction of his relational theory.

I am not presently concerned to enter into the debate about whether perfectionism is objectionably self-regarding. My question is rather whether Metz's objection should be understood as a criticism of the original framework of ubuntu, or whether, as he believes, it specifies a constraint on the interpretation of the concept. The answer must be that if the unifying principle is part of the conceptual framework of the source language, then the objection counts as an objection to the framework, not an argument in favour of a different interpretation of it.

30 For example, Metz emphasises the first sense in his remark that Godfrey Onah's "conception of respect for human dignity is more African in flavour" than Judge Yvonne Mokgoro's Kantian interpretation (2007a: 329). However, it is striking that Metz does not fault Judge Mokgoro's Kantian interpretation for its potential infidelity to the African tradition, but for its lack of unifying power.

31 I here set aside certain qualms I have about Metz's formulation of the perfectionist interpretation of ubuntu. 
Consider how this plays out in a Metzian theory of $\sigma \omega \varphi \rho o \sigma u ́ v \eta$. Since the moral intuitions are within the tradition unified by the virtue concepts, the objection needs to be recast in terms of perfectionism's being a poor explanation for the virtuousness of the virtue concepts. But since there are (or: if there are) in the original ethical language conceptual connections between virtue, the good, and human selfrealisation, conceptual transposition that does not recognise these connections will be distorted and inaccurate. Even if the goal is systematic transposition of the concept, the goal of fidelity to the source language cannot be set aside. For if it were, and the original concept were defined in part by its relationship to other concepts in the ethical vocabulary, it might not be reproduced at all.

Probably Metz would argue in response that his goal is to present a theory growing out of African ethical commitments, a claim that is indeed expressed at several junctures in his paper (e.g. 322 and 340). This would be to admit that the dialectical role of the critique of perfectionism is to move outside of the tradition and to become answerable to more general constraints of plausibility - and in particular, plausibility to a Western philosophical audience.

Three points can be made in response. First, this manoeuvre would apparently require Metz to give up on his claim that "there is strong epistemic reason to hold [the theory], in relation to certain moral intuitions common to sub-Saharan Africa and in comparison to other theoretical expressions of African morality" (322). Secondly, he would then risk presenting a theory in which neither Western people nor sub-Saharan Africans find themselves reflected,$^{32}$ a theory that resonates with no one. Thirdly, Metz is not really in a position to know that the original conceptual framework - in which, perhaps, virtue was logically related to self-realisation - must be abandoned. For, as is clear from the description of his method given at the beginning of the section, Metz does not conduct what could be termed "ethical exegesis" - that is, the articulation, clarification, and deepening of the African tradition's understanding of its own ethical concepts. But since this implies that he tries to perform the systematic transposition without a clear understanding of the role of ubuntu in the source vocabulary, it is hard to see how he could know that the original framework needs to be abandoned. One can't know that the external criticism holds until one understands the possibilities open to the reconstruction in terms of the source language.

\section{7.}

In summary, I have argued that no reasonable transposition of the Metzian sort is possible without a clearer understanding of the logic of the concept of ubuntu. In particular, it needs to be determined whether ubuntu is a virtue conceptually

32 I here echo a phrase used by Metz in unpublished work. 
connected to human self-realisation, whether it is one of a plurality of fundamental virtues or the fundamental virtue, or perhaps, a term for virtue itself. ${ }^{33}$

\section{REFERENCES}

Eze, M.O. 2010. Intellectual history in contemporary South Africa. New York: Palgrave Macmillan.

Gade, C.B. 2012. What is Ubuntu? Different interpretations among South Africans of African descent. South African Journal of Philosophy 31: 484-503.

Garland, R. 2008. Daily life of the Ancient Greeks. London: The Greenwood Press.

Gyekye, K. 2011. African ethics. Stanford encyclopedia of philosophy. Edited by N. Zalta, URL $=<\mathrm{http}: / /$ plato.stanford.edu/archives/fall2011/entries/african-ethics/ $>$.

Hamilton, E. and Cairns, H. 1961. The collected dialogues of Plato: Including the letters. New York: Pantheon Books.

Harper, D. 2007. Online etymology dictionary. www.etymonline.com.

Hlatshwayo, M. 2010. Ukwehla Ngesilulu: Origination in KwaZulu-Natal, http://www. archivalplatform.org/blog/entry/ukwehla_ngesilulu/.

Laband, J. 1995. Rope of sand: The rise and fall of the Zulu Kingdom in the nineteenth century. Johannesburg: Jonathan Ball.

Mandela, N. 2006. www.youtube.com/watch?v=HED4h00xPPA

Metz, T. 2007a. Toward an African moral theory. South African Journal of Political Philosophy 15: $321-41$.

Metz, T. 2007b. The motivation for "Toward an African moral theory". South African Journal of Philosophy 26: 331-35.

Metz, T. 2007c. Ubuntu as a moral theory: Reply to four critics. South African Journal of Philosophy 26: 369-87.

North, H.F. 1948. The concept of Sophrosyne in Greek literary criticism. Classical Philology 43: $1-17$.

Ramose, M.B. 1999. African philosophy through Ubuntu. Harare: Mond Publishers.

Ramose, M.B. 2007. But Hans Kelsen was not born in Africa: A reply to Thaddeus Metz. South African Journal of Philosophy 26: 347-355.

Schmid, W.T. 1981. Socrates' practice of Elenchus in the Charmides. Ancient Philosophy 1: 14147.

Shutte, A. 2001. Ubuntu: An ethic for a new South Africa. Cape Town: Cluster Publications.

Tutu, D. 2000. No future without forgiveness. New York: Random House.

33 This paper grew out of a presentation given at a workshop on Thad Metz's manuscript Relational ethics: An African ethical theory at the University of Johannesburg in June 2015. I owe thanks to Hennie Lötter and Thad Metz for the invitation to participate, and to the latter, for his responses to my presentation. In addition, I would like to thank two anonymous referees for Phronimon for their constructive commentary and Mrs Lanie van Kradenburg for expert guidance during the editorial process. 
Van Niekerk, J. 2013. Ubuntu and moral value. PhD thesis, University of the Witwatersrand, Johannesburg, South Africa.

Waetjen, T. 2004. Workers and warriors: Masculinity and the struggle for nation in South Africa. Chicago: University of Illinois Press.

Williams, B. 1985. Ethics and the limits of philosophy. London: Fontana Press/Collins. 